\title{
Hypoxia induces the expression of the pro-apoptotic gene BNIP3
}

\author{
K Guo', G Searfoss ${ }^{1}$, D Krolikowski ${ }^{1}$, M Pagnoni ${ }^{1}$, C Franks ${ }^{1}$, \\ $K$ Clark ${ }^{1}, K T \mathrm{Yu}^{1}, \mathrm{M}$ Jaye $^{1,2}$ and $\mathrm{Y}$ Ivashchenko ${ }^{*, 1}$ \\ 1 Cardiovascular Biology, AVENTIS PHARMA, Room 245, Industriepark Hochst, \\ H825, 65926 Frankfurt a. Main, Germany \\ 2 Current address: SmithKline Beecham Pharmaceuticals 709 Swedeland Rd. \\ UW2511, King of Prussia, PA 19406-0939 \\ * Corresponding author: Y Ivashchenko, Cardiovascular Biology, AVENTIS \\ PHARMA, Room 245, Industriepark Hochst, H825, 65926 Frankfurt a. Main, \\ Germany. Tel: 49-69-305-18574; Fax: 49-69-305-12796; \\ E-mail: yuri.ivashchenko@aventis.com
}

Received 8.5.00; revised 25.10.00; accepted 8.11.00

Edited by CJ Thiele

\begin{abstract}
It has been shown that oxygen deprivation results in apoptotic cell death, and that hypoxia inducible factor 1 (HIF1) and the tumor suppressor 553 play key roles in this process. However, the molecular mechanism through which hypoxia and HIF1 induce apoptosis is not clear. Here we show that the expression of pro-apoptotic gene BNIP3 is dramatically induced by hypoxia in various cell types, including primary rat neonatal cardiomyocytes. Overexpression of HIF1 $\alpha$, but not p53, induces the expression of BNIP3. Overexpression of BNIP3 leads to a rather unusual type of apoptosis, as no cytochrome $c$ leakage from mitochondria was detected and inhibitors of caspases were unable to prevent cell death. Taken together, these data suggest that HIF1-dependent induction of BNIP3 may play a significant role during hypoxiainduced cell death. Cell Death and Differentiation (2001) 8, 367 376.
\end{abstract}

Keywords: BNIP3; hypoxia; cardiomyocytes; apoptosis

Abbreviations: BNIP3, the E1B 19K/Bcl-2-binding protein Nip3; caspases, cysteine-dependent aspartate-specific proteases; BSA, bovine serum albumin; GAPDH, glyceraldehyde-3-phosphate dehydrogenase; HeLa, human cervical carcinoma cell line; mAb, monoclonal antibody; nt, nucleotide; PAGE, polyacrylamide gel electrophoresis; PBS, calcium- and magnesium-free phosphatebuffered saline; SDS, sodium dodecyl sulfate; zVAD-fmk, Nbenzyloxycarbonyl-derivative of synthetic tripeptide VAD (Val-AlaAsp) coupled to fluoromethylketone

\section{Introduction}

Programmed cell death (apoptosis) is regulated by gene products that either promote or suppress cell death. Bcl-2 and $\mathrm{Bcl}-\mathrm{x}$, the prototype cell death suppressors which are related to ced- 9 of Caenorhabditis elegans, are key regulators of cell survival. ${ }^{1-3}$ Additional members of the Bcl-2-family with proapoptotic activity, such as Bak, Bax, Bad, Bik, Bid, BNIP3 and $\mathrm{Nix}$ etc. have been identified, as have anti-apoptotic members, including MCL-1, A1, etc. (for a review, see ${ }^{4}$ ). The ratio of anti- and pro- apoptotic molecules (such as Bcl-2/ Bax) determines the response to death signals. ${ }^{5,6}$ Indeed, overexpression of pro-apoptotic genes induces programmed cell death even in the absence of any other physiological or pathological stimuli. Many $\mathrm{Bcl}-2$ family proteins have a $\mathrm{COOH}$-terminal transmembrane domain that allows their association with the outer mitochondrial membrane. ${ }^{7,8}$ There is growing evidence that mitochondrial function is disturbed early in the apoptotic response and may be important in mediating apoptosis. ${ }^{9,10}$ This is often seen as the loss of mitochondrial membrane potential and the release of cytochrome $c,^{11-13}$ that leads to formation of a complex consisting of APAF1, procaspase-9, cytochrome $c$, and ATP or dATP. ${ }^{11,14}$ Possibly other components, including other caspases, are recruited to this complex ${ }^{15}$ which ultimately leads to the processing of procaspase- 9 to the mature enzyme. Activated caspase- 9 in turn cleaves and activates caspase-3, a protease that is involved in apoptosis induced by various stimuli. ${ }^{16}$ The critical role of Bcl-2 family members in regulating this pathway has been demonstrated by blockage of cytochrome $c$ release from mitochondria and prevention of apoptotic cell death by overexpression of the anti-apoptotic gene Bcl-2, and by induction of mitochondrial dysfunction and apoptosis by overexpression of the pro-apoptotic gene Bax. $^{6,13,17}$

Tissue injury resulting from deprivation of oxygen is involved in the development of various diseases, such as stroke and myocardial infarction. It is believed that apoptotic cell death plays a significant role in ischemiainduced tissue injury. ${ }^{18,19}$ Hypoxia inducible factor 1 (HIF1), a heterodimeric basic helix-loop-helix-PAS domain (bHLH-PAS) transcription factor regulates expression of genes that are affected by hypoxia, such as those involved in glycolysis, angiogenesis and erythropoiesis. Indeed, HIF1 stimulates the expression of its downstream target genes, such as vascular endothelial growth factor $A$ (VEGF-A), erythropoietin-1, heme oxygenase 1 (OX1), glucose transporter 1 (GLUT1), and other enzymes involved in glycolysis (for review, $\operatorname{see}^{20,21}$ ) by binding to the hypoxia-response element (HRE) with the core sequence $5^{\prime}$-CGTG-3', which is present in the promoter regions of these genes. The expression of $\operatorname{HIF} 1 \alpha$, a subunit of $\mathrm{HIF} 1$, is precisely regulated by the concentration of $\mathrm{O}_{2}$, such that levels of HIF1 $\alpha$ protein and HIF1 DNA-binding activity increase exponentially as $\mathrm{O}_{2}$ concentration decreases. $^{22}$ A role for HIF1 $\alpha$ in cell death was suggested by the ability of hypoxia and hypoglycemia to increase apoptosis in wild-type (HIF1 $\alpha^{+/+}$) embryonic stem cells (ES), but not in HIF $1 \alpha^{-1-}$ ES cells. ${ }^{23}$ However, the molecular mechanisms through which hypoxia and HIF1 $\alpha$ induce 
programmed cell death were not clarified. ${ }^{24}$ It was shown that HIF1 mediates increased activity of the tumor suppressor gene p53 upon hypoxia as a result of stabilization of $\mathrm{p} 53,{ }^{25}$ though the relevance of increased p53 expression in hypoxia-induced cell death is not clear. Recent results indicate that p53 stimulates proteasomemediated degradation of $\mathrm{HIF} 1 \alpha,{ }^{26}$ possibly representing a negative regulatory feedback loop.

To understand the molecular mechanisms underlying hypoxia-induced cell death, we generated a rat cardiomyocyte subtracted cDNA library of hypoxia-induced genes and interrogated this library by a cDNA microarray approach. Our results reveal that mRNA and protein levels of BNIP3, a pro-apoptotic gene, are dramatically increased during hypoxia. Overexpression of $\mathrm{HIF} 1 \alpha$, but not of $\mathrm{p} 53$, induced the expression of BNIP3, suggesting that the induction of BNIP3 by HIF1 was direct and independent of p53. Overexpression of BNIP3 resulted in cell death, through mechanisms not involving activation of caspase 3 or 9 or cytochrome $c$ release. Our data suggest that increased expression of the pro-apoptotic, mitochondria-anchored ${ }^{27}$ protein BNIP3 contributes to hypoxia- and HIF1- induced cell death.

\section{Results}

\section{Hypoxia dramatically induces the expression of BNIP3}

To investigate the effect of hypoxia on gene expression, and particularly expression of genes involved in cell death/survival, neonatal cardiomyocytes were subjected to normoxia or hypoxia for $16 \mathrm{~h}$, mRNA isolated, and a subtracted cDNA library enriched for hypoxia-induced transcripts prepared as described in Materials and Methods. Minipreparations of plasmid DNA from 8000 colonies from the subtracted library were generated, the cDNA inserts of these were end-sequenced and BLAST analysis against GenBank was performed. Strikingly, 120 clones were found to have high homology to different regions (non-coding and open reading frame) of mouse BNIP3 cDNA. Detailed analysis of these sequences confirmed that all of them represent the rat homolog of the pro-apoptotic E1B19K-binding protein BNIP3 ${ }^{28}$ and this rat BNIP3 sequence has been deposited in GenBank (Accession Number AF243515). The predicted rat BNIP3 protein shares $99 \%$ identity with mouse BNIP3 protein, differing only by two conserved amino acid substitutions (mouse residues 77 (thr) and 100 (val) are ser and ile, respectively in rat BNIP3, Y Ivashchenko et al, unpublished).

Microarray analysis of the hypoxia-enriched subtracted library by hybridization with control and hypoxic probes confirmed the strong upregulation of BNIP3 in the hypoxiatreated cells (Figure 1). According to our microarray analysis, BNIP3 was induced more than threefold, (average $3.6 \pm 1.2$ ) by hypoxia. In contrast, controls such as actin and GAPDH cDNAs or arabidopsis DNA showed equal or no signals, respectively (Figure 1). To further validate this result, the expression of BNIP3 in neonatal cardiomyocytes under normoxic and hypoxic conditions
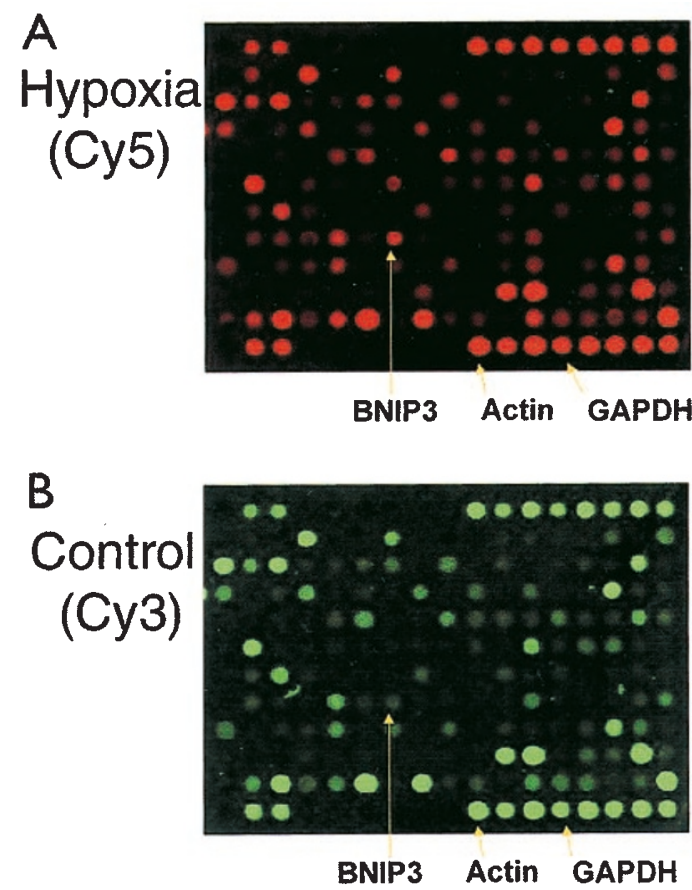

Figure 1 Hybridization of Cy-dye labeled cRNA to an arrayed rat hypoxic cardiomyocyte subtracted library. A mixture of Cy3-labeled (control) and Cy5labeled (hypoxia) cRNA probes in formamide hybridization buffer was hybridized to an array of 3840 genes on aluminum-coated slides and processed as described in Materials and Methods. A representative BNIP3 spot and actin and GAPDH controls are indicated by arrows. The ratio (hypoxia:control) of normalized intensities are : BNIP3: 4.0; Actin: 1.0; GAPDH: 1.0

was examined by Northern blot analysis. As shown in Figure 2, the expression of BNIP3 was significantly induced at both 8 and $24 \mathrm{~h}$ of hypoxia. To test whether the induction of BNIP3 by hypoxia is specific to rat cardiomyocytes or represents a more general phenomenon, the effect of hypoxia on BNIP3 expression was tested in several other cell types, including human HeLa cells and mouse hepatoma cell line HePa1-6. Expression of BNIP3 was induced by hypoxia in these cells similar to the induction observed in neonatal cardiomyocytes (data not shown).

To investigate the time course of BNIP3 induction by hypoxia, HeLa cells were subjected to hypoxia for various lengths of time, and RNA was isolated for Northern blot analysis. Hypoxia induced BNIP3 expression as early as $3 \mathrm{~h}$ (Figure $3 \mathrm{~A}$ ), which was very similar to the induction pattern of VEGF-A (Figure 3B). At later time points, e.g. 12 and $24 \mathrm{~h}, \mathrm{BNIP} 3 \mathrm{mRNA}$ levels further increased while VEGF-A mRNA levels peaked at $6-9 \mathrm{~h}$ and declined thereafter. These data suggest that the induction of BNIP3 and VEGF-A by hypoxia may share some common pathways, and further suggest that BNIP3 and VEGF-A mRNAs may be differentially regulated post-transcriptionally. VEGF-A mRNA is known to be extremely unstable, a phenomenon which is due to destabilizing elements located in various regions in the mRNA. ${ }^{29}$ Interestingly, the BNIP3 transcripts (human, mouse and rat) also contain multiple 


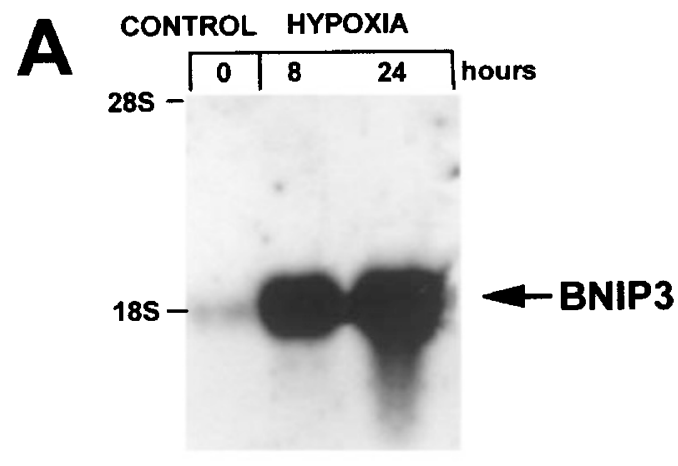

B

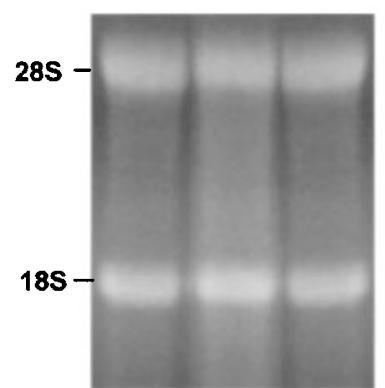

Figure 2 BNIP3 mRNA is upregulated by hypoxia in neonatal rat cardiomyocytes. (A) Northern blot analysis of total RNA derived from control (normoxic, lane 1) or hypoxic (lane $2,8 \mathrm{~h}$; lane $3,24 \mathrm{~h}$ ) cells. Details are described in Materials and Methods. (B) Ethidium bromide staining of the RNA samples is shown as a control for equal loading

CONTROL HYPOXIA

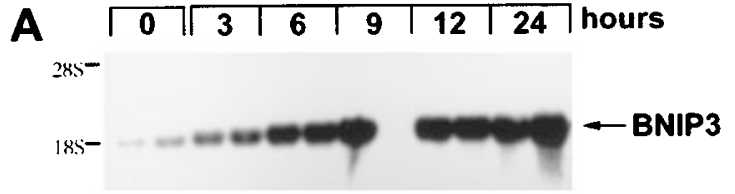

B
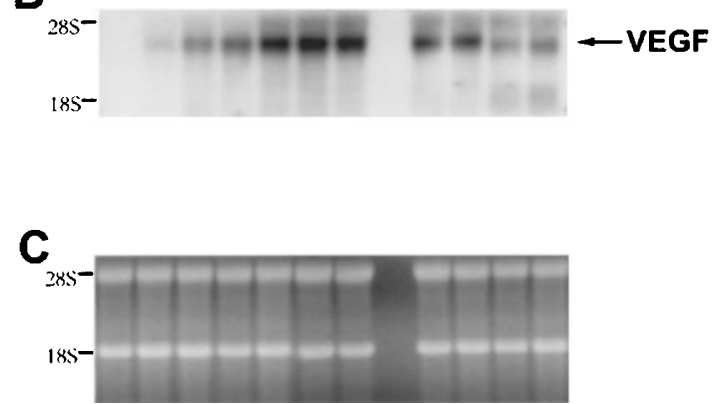

Figure 3 Time course of BNIP3 and VEGF-A mRNA expression in hypoxiatreated HeLa cells. Northern blot analysis of total RNA derived from control (normoxic) or HeLa cells exposed to hypoxia for the indicated number of hours. Each duplicate time point represents an individual RNA sample from a $10 \mathrm{~cm}$ dish. One of the samples ( $9 \mathrm{~h}$ of hypoxia) was completely degraded. (A) Hybridization with BNIP3 probe. (B) Rehybridization of blot with VEGF-A probe, after stripping of BNIP3 probe. (C) Ethidium bromide staining of the RNA samples is shown as a control for equal loading potential destabilizing AUUU elements in $3^{\prime}$ UTR (Y Ivashchenko, unpublished).

\section{Hypoxia induces accumulation of the BNIP3 protein in cells}

To study whether accumulation of the BNIP3 mRNA leads to elevated levels of BNIP3 protein, immunoblotting analysis was performed using total cell lysates from control HeLa cells and cells subjected to hypoxia for $16 \mathrm{~h}$ (Figure 4). In control cells, no BNIP3 protein was detected but after hypoxia a band migrating at $\sim 28 \mathrm{kDa}$, was detected by immunoblotting with specific anti-BNIP3 antiserum (see Materials and Methods). It has been reported that even recombinant BNIP3 protein expressed in transfected cells was rapidly degraded and that proteasome inhibitors partially blocked BNIP3 proteolysis. ${ }^{30}$ We therefore examined whether the proteasome inhibitor, lactacystin, could increase BNIP3 protein accumulation during hypoxia. At concentrations of 10 and $20 \mu \mathrm{M}$, lactacystin treatment during hypoxia significantly enhanced the accumulation of BNIP3 protein (Figure 4). Thus, under hypoxic conditions, BNIP3 protein is degraded at least partially via a proteasome pathway. Pulse chase experiments under conditions of hypoxia $+/-$ proteasome inhibitors will be required to assess the half-life of BNIP3 protein and the contribution of proteasome vs non-proteasome pathways to BNIP3 protein stability. Rapid turnover of BNIP3 protein may be an important cytoprotective mechanism. In contrast, no BNIP3 protein was detected in cells incubated under normoxic conditions, even in the presence of proteasome inhibitor (Figure 4). This suggests that expression of endogenous BNIP3 protein is negligibly weak under normal oxygen conditions, in good agreement with the very low levels of BNIP3 mRNA in normoxic cells (Figures 2 and 3 ).

\section{HIF1a, but not p53 induces BNIP3 expression}

Since the time course of induction of BNIP3 and VEGF-A transcripts are quite similar (Figure 2), we tested whether, like VEGF-A, ${ }^{31}$ the induction of BNIP3 was mediated via HIF1,

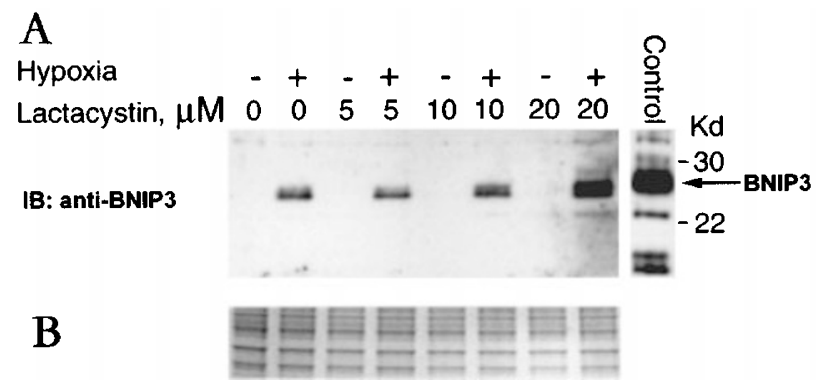

Figure 4 Induction of upregulation of BNIP3 protein by hypoxia and the proteasome inhibitor lactacystin. HeLa cells grown in $35 \mathrm{~mm}$ wells were exposed to normoxic or hypoxic conditions for $16 \mathrm{~h}$ with or without lactacystin (Biomol) at the indicated concentrations. (A). BNIP3 was detected by immunoblotting as described in Materials and Methods. A lysate of HeLa cells transfected with CMV-BNIP3 expression vector was used as positive control. (B) As a control for equal loading of cell lysates, the same samples were resolved by SDS-PAGE and the gel stained with Coomassie blue 
and if so, whether this was a direct or indirect effect. HeLa cells were infected with a recombinant adenovirus expressing HIF $1 \alpha(\mathrm{AV}-\mathrm{HIF} 1 \alpha)$ and control cells were infected with a recombinant adenovirus expressing $\beta$-galactosidase. Twentyfour hours post infection, RNAs were isolated and the expression of BNIP3 was examined by Northern blot analysis. As shown in Figure 5, overexpression of $\mathrm{HIF} 1 \alpha$ strongly induced the expression of BNIP3 in HeLa cells, similar to induction caused by hypoxia, while the control virus was without effect on BNIP3 expression. This result suggested that HIF1 $\alpha$ is sufficient for induction of BNIP3. To test whether HIF1 $\alpha$ directly induces BNIP3, or whether BNIP3 induction by $\mathrm{HIF} 1 \alpha$ is mediated by other components, such as the hypoxia-induced tumor suppressor protein $\mathrm{p} 53,{ }^{32} \mathrm{HeLa}$ cells were infected with a recombinant adenovirus expressing p53 (AV-p53), and $24 \mathrm{~h}$ postinfection, RNA was isolated and the expression of BNIP3 was examined by Northern blot analysis. As shown in Figure 5, infection of HeLa cells with AV-p53 had little or no effect on the expression of BNIP3. On the other hand, AV-p53, but not AV-HIF1 $\alpha$ or hypoxia, induced the expression of the pro-apoptotic gene Bax, presumably by binding to the p53-DNA binding sites present within the promoter region of the Bax gene. ${ }^{33}$ These data demonstrate that $\mathrm{p} 53$ is not involved in the induction of BNIP3 by hypoxia or $\mathrm{HIF} 1 \alpha$ and indicate that BNIP3 induction by hypoxia is likely directly mediated by $\mathrm{HIF} 1 \alpha$.

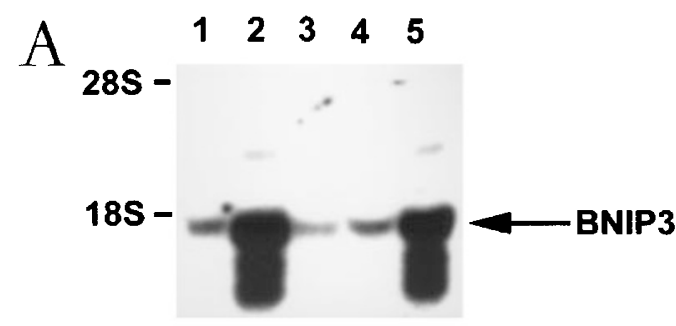

$\mathrm{B}$
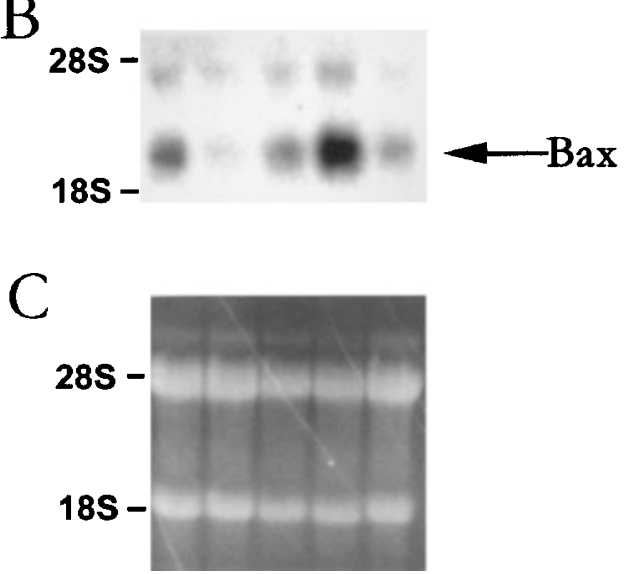

Figure $5 \mathrm{HIF} 1 \alpha$, and not p53, induces expression of BNIP3 in HeLa cells. Northern blot analysis of total RNA derived from control HeLa cells (lane 1) or HeLa cells infected with the HIF $1 \alpha$ adenovirus (lane 2), $\beta$-galactosidase adenovirus (lane 3 ) or p53 adenovirus (lane 4). RNA from non-infected cells grown under hypoxic conditions for $16 \mathrm{~h}$ is shown in lane 5. (A) Hybridization of Northern blot to BNIP3 probe. (B) Rehybridization of blot with Bax probe, after stripping of BNIP3 probe. (C) Ethidium bromide staining of the RNA samples is shown as a control for equal loading

\section{Caspase- 9 and caspase- 3 are not involved in BNIP3 induced cell death}

To investigate the molecular pathways through which BNIP3 induces apoptotic cell death, ${ }^{34-36}$ a recombinant adenovirus expressing BNIP3 (AV-BNIP3) was constructed. As expected, infection of HeLa cells with AV-BNIP3 led to dramatic cell death, in a dose-dependent manner (Figure 6), while infection of cells with a control $\beta$-galactosidase expressing adenovirus, AV- $\beta$-gal, had no effect on cell viability at the same multiplicity of infection $(\mathrm{MOI}=10)$. Even at $5-10$ times higher multiplicity of infection, AV- $\beta$-gal did not cause significant cytotoxicity and, therefore, cell killing induced by AV-BNIP3 infection depends on expression of BNIP3 protein and is independent of adenoviral general toxicity. Mitochondria, particularly the mitochondrial protein cytochrome $c$, play significant roles in regulation of apoptotic cell death. It has been reported that apoptosis inducing factors, such as Bax, ${ }^{6}$
A
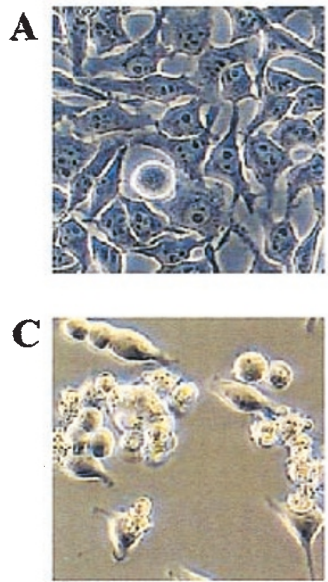

E

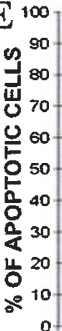

B

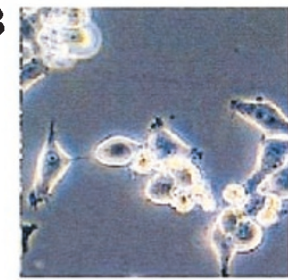

D
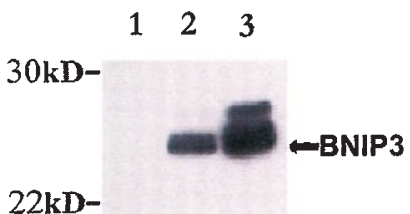

b-gal

ab-gal

ab-gal+zVAD

ab-gal+LEHD

- BNIP3

$\square B N I P 3+Z V A D$

$\because B N I P 3+L E H D$

-FAS-Ab+zVAD

$F A S-A b+L E H D$
-FAS-Ab

EXPRESSION CONSTRUCTS AND TREATMENTS

Figure 6 Overexpression of BNIP3 in HeLa cells induces cell death which is not prevented by caspase inhibitors. HeLa cells in 6-well plates were infected with the control Ad- $\beta$-gal, $3 \times 10^{7}$ viral particles per $\mathrm{ml}, \mathrm{vp} / \mathrm{ml}, \mathrm{MOl}=10,(\mathbf{A})$ or Ad-BNIP3 adenovirus (B and $\mathbf{C}$ ) at $1 \times 10^{7} \mathrm{vp} / \mathrm{ml}, \mathrm{MOl}=10,(B)$ or $3 \times 10^{7} \mathrm{vp} / \mathrm{ml}$, $\mathrm{MOI}=30$. Twenty-four hours post infection, cells were photographed using an inverted phase contrast microscope. Cells in additional wells were lysed and processed for immunoblotting with anti-BNIP3 antibodies, (D) Lane 1: lysate from Ad-b-gal infected cells; Lane 2: Iysate from cells infected with $1 \times 10^{7} \mathrm{vp} /$ ml Ad-BNIP3: Lane 3: Iysate from cells infected with $3 \times 10^{7} \mathrm{vp} / \mathrm{ml}$ Ad-BNIP3. (E) HeLa cells were transfected with a plasmid expressing $\beta$-galactosidase, treated with caspase inhibitors zVADfmk $(20 \mu \mathrm{M})$ or LEHD $(20 \mu \mathrm{M})$ and infected with adenoviruses expressing either $\beta$-gal or BNIP3. As a control for zVAD activity, cells were treated with anti-FAS antibodies to induce apoptosis and untreated or treated with $\operatorname{ZVAD}(10 \mu \mathrm{M})$. The percentage of apoptotic cells was calculated as described in Materials and Methods 
induces cytochrome $c$ leakage from mitochondria into cytosol, thereby inducing the activity of caspase- 9 and caspase-3, proteolytic enzymes that are key executors of apoptosis induced by various stimuli. Since BNIP3 was reported to be a mitochondria-anchored protein, ${ }^{27}$ we were interested in testing whether overexpression of BNIP3 causes mitochondria damage and leakage of cytochrome $c$. To test this, cells were infected with AV-BNIP3, and mitochondria and cytosol were fractionated and the localization of cytochrome $c$ was examined by Western blot analysis. As a positive control, cells were treated with staurosporine for $6 \mathrm{~h}-\mathrm{a}$ treatment known to cause cytochrome $c$ accumulation in cytosol. As shown in Figure 7, the cytosol of cells treated with staurosporine contained a significant level of cytochrome $c$, whereas no cytochrome $c$ was detected in the cytosol of cells infected with Av-BNIP3 or the control, $\beta$-galactosidase adenovirus.

The activation of caspases, such as caspase-3, and 9, is important for the execution of programmed cell death induced by various agents. Inhibition of these caspases by their specific tri/tetra-peptidic inhibitors, such as zVAD (for caspase-3) and LEHD (for caspase-9) blocks apoptosis induced by appropriate stimuli, for example by anti-Fas antibodies. $^{37}$ To investigate whether caspase-3 or caspase9 is involved in BNIP3 induced cell death, cells were infected with AV-BNIP3 in the presence or absence of $20 \mu \mathrm{M} z V A D$ or LEHD. These peptidic inhibitors had little or no effect on cell death induced by overexpression of BNIP3, though zVAD effectively blocked anti-Fas induced apoptosis, even at as low as $10 \mu \mathrm{M}$ concentration (Figure $6 \mathrm{E})$. Taken together, these data demonstrate that the release of cytochrome $c$ from mitochondria to cytosol, and the subsequent activation of caspase- 9 and caspase-3-the central components of apoptosis pathways in various models-are not involved in cell death induced by BNIP3 overexpression.

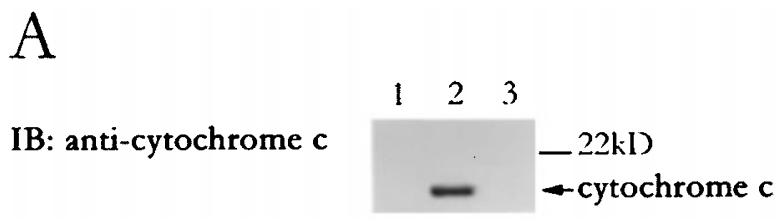

$\mathrm{B}$

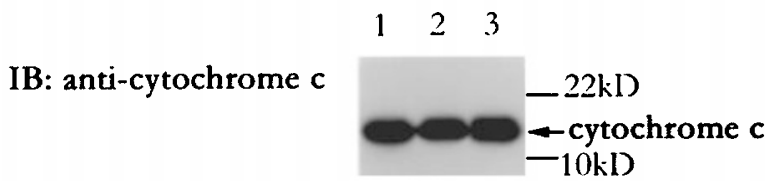

Figure 7 Overexpression of BNIP3 does not cause cytochrome $c$ leakage from mitochondria. HeLa cells were either infected $\left(3 \times 10^{7} \mathrm{vp} / \mathrm{ml}\right)$ with adenovirus expressing $\beta$-galactosidase (lane 1) or BNIP3 (lane 3 ), or treated with $1 \mu \mathrm{M}$ staurosporine (lane 2). Cells were lysed in SDS sample buffer after $24 \mathrm{~h}$ of adenovirus infection or $4 \mathrm{~h}$ of staurosporine treatment. Cytosolic $(\mathbf{A})$ and mitochondrial (B) fractions were prepared as described in Materials and Methods and nitrocellulose blots were probed with anti-cytochrome $c$ monoclonal antibodies. Staurosporine treatment induced cytochrome $c$ leakage into cytosol, while expression of BNIP3, or the negative control, $\beta$ galactosidase, did not

\section{Discussion}

Hypoxia is an essential physiological and pathological stimulus which plays a key role in the development of cancer, heart attack and stroke-major causes of mortality. Hypoxia induces a spectrum of responses, the majority of which are adaptive in nature, including erythrogenesis, angiogenesis and increased glycolysis. Genes that are critical for the adaptation to hypoxia include erythropoietin (EPO), vascular endothelial growth factor (VEGF-A), inducible nitric oxide synthase (iNOS), heme oxygenase (HO1), glucose transporter 1 (GLUT1), and glycolytic enzymes such as aldolase $A$, enolase 1 , lactate dehydrogenase $A$, phosphofructokinase $L$, and phosphoglycerate kinase $1.21,31$ Currently however, the mechanisms by which hypoxia stimulates cell death are poorly understood. Hypoxiainducible factor 1 (HIF1), a heterodimeric basic helix-loophelix-PAS domain (bHLH-PAS) transcription factor consisting of HIF $1 \alpha$ and HIF $1 \beta / A R N T$, plays a key role in the transcriptional induction of genes involved in adaptive responses to hypoxia. Expression of the HIF $1 \alpha$ subunit is precisely regulated by the cellular $\mathrm{O}_{2}$ concentration, such that the level of HIF $1 \alpha$ and the DNA binding activity of HIF1 increases exponentially as the $\mathrm{O}_{2}$ concentration decreases. By binding to the hypoxia-response element (HRE, with the core sequence of $5^{\prime}$ CGTG-3') present in the promoter/ enhancer region of target genes, HIF1 increases the expression of these target genes in response to hypoxia. Indeed, the induction of these genes by hypoxia is severely impaired in cells derived from HIF $1 \alpha^{-1-}$ mice. ${ }^{23}$

In an attempt to identify novel cellular responses to hypoxia, we generated a neonatal rat cardiomyocyte subtracted cDNA library enriched for hypoxia-upregulated genes. The cDNA inserts of this library were sequenced, annotated, and subjected to microarray analysis with probes derived from normoxic and hypoxic rat cardiomyocytes. One of the most strikingly upregulated genes identified in this study was the pro-apoptotic gene BNIP3. Additional studies revealed that upregulation of BNIP3 by hypoxia was not unique to neonatal rat cardiomycytes, but was also observed in various other cell types, such as HeLa cells (Figures 3 and 4), human skeletal muscle cells, and adult rat cardiomyocytes (data not shown).

BNIP3 was originally identified in a yeast two hybrid screen for proteins which bind to the adenovirus E1B $19 \mathrm{kDa}$ protein, a viral gene product which protects against cell death induced by certain stimuli including viral infection. $^{28}$ BNIP3 is a $21 \mathrm{kDa}$ protein capable of homodimerization as well as heterodimerization with the antiapoptotic protein $\mathrm{Bcl}-2 .{ }^{27,30,38}$ BNIP3 contains a membrane-anchoring domain and a $\mathrm{BH} 3$ (Bcl-2 homology 3) domain, the former implicated in mitochondrial targeting and the latter implicated in dimerization and induction of cell death upon overexpression in some but not all ${ }^{39}$ studies. BNIP3 was one of eight apoptosis-related genes significantly underexpressed in keloid tissues. Its decreased content may contribute to the continued production of connective tissue which is the hallmark of this disease. ${ }^{34}$ The genome of the nematode $C$ elegans contains a BNIP3 homolog, ceBBNIP3, whose product 
induces apoptosis when co-expressed with CED-3, the $C$. elegans homolog of caspase $3 .^{35}$ Indeed, ceBBNIP3, CED3 , and CED-9, the $C$. elegans homolog of $\mathrm{Bcl}-2$, can exist in a ternary complex. ${ }^{35}$

Since we found BNIP3 to be strongly upregulated by hypoxia in neonatal rat cardiomyocytes, and BNIP3 overexpression induces apoptosis in a variety of cell types, we investigated the mechanism and significance of BNIP3 induction by hypoxia. It has been reported that the expression of the tumor suppressor gene p53 is increased upon hypoxia through a HIF1-dependent pathway. ${ }^{25}$ Thus, we examined whether upregulation of BNIP3 by hypoxia was p53 dependent or independent. Overexpression of HIF1 $\alpha$ but not p53 induced the expression of BNIP3. In contrast, only overexpression of $\mathrm{p} 53$, as expected ${ }^{33}$ but not HIF1 $\alpha$ upregulated transcription of another pro-apoptotic gene-Bax. Thus, hypoxia directly upregulates BNIP3 expression, via a p53-independent mechanism.

The upregulation of BNIP3 by HIF $1 \alpha$ but not p53 was paralleled by their effects on apoptosis in HeLa cells, which was observed in response to BNIP3 overexpression (Figure 6) but not in response to p53 overexpression (data not shown). In our hands, HeLa cells and rat cardiomyocytes are relatively resistant to hypoxia-induced cell death, which is delayed as compared to the kinetics of hypoxia-induced upregulation of BNIP3 (data not shown). The delayed accumulation of BNIP3 protein and its apparent catabolism by mechanisms at least partly involving proteasomes (Figure 4) may be responsible for slow progression of hypoxia/BNIP3-mediated cell death. Alternatively, hypoxia may affect the expression of other pro- or anti-apoptotic genes, in the context of which strong upregulation of BNIP3 by hypoxia may be insufficient to trigger apoptosis. Thus, hypoxia-induced transcriptional upregulation of BNIP3 expression may represent an important component of the pro-apoptotic influence of hypoxia, but by itself may be insufficient to trigger apoptosis in this context. However, under conditions of normal oxygen tension, adenovirusdriven BNIP3 overexpression is clearly sufficient to evoke cell death (Figure 6). Overexpression of BNIP3 using conventional transfection with CMV-driven BNIP3 expression construct also causes significant cell death (data not shown) though adenovirus-mediated BNIP3 expression lead to more efficient cell killing as close to $100 \%$ of cells are infected, in comparison with only 50-60\% efficiency of transfection. Upon viral infection or BNIP3 cDNA transfection, level of BNIP3 expression was much higher than induced by hypoxia that could explain why a killing effect of BNIP3 adenovirus infection was stronger than hypoxia.

Mitochondrial damage and release of cytochrome $c$ from the mitochondria to the cytosol accompany apoptotic cell death induced by various stimuli. ${ }^{11-13,40}$ Together with dATP, cytochrome $c$ triggers the association of procaspase- 9 with Apaf-1. The formation of a cytochrome c/ dATP/caspase-9/Apaf-1 complex leads to the cleavage and activation of caspase-9. Activated caspase-9, in turn, cleaves and activates caspase-3, which is crucial for the execution of apoptosis in various models. It has been reported that pro-apoptotic factors which contain a $\mathrm{BH} 3$ domain, such as Bid and Bax, induce mitochondrial damage and cause the release of cytochrome $c$ into the cytosol. ${ }^{41}$ Overexpression of anti-apoptotic factors, such as $\mathrm{Bcl}-2$ and $\mathrm{Bcl}-\mathrm{XL}$, blocks cytochrome $c$ release from mitochrondia and inhibits apoptosis. ${ }^{12,13}$ Since BNIP3 has been demonstrated to be localized on mitochrondrial membranes, we speculated that BNIP3 might induce apoptotic cell death by causing cytochrome $c$ release from mitochondria, similar to Bid and Bax. In order to further examine the mechanisms of BNIP3 induced cell death, HeLa cells were infected with recombinant adenoviruses expressing either BNIP3 or, as control, $\beta$-galactosidase and the requirement for caspases- 3 and -9 and the cellular distribution of cytochrome $c$ examined. Our data demonstrate that although overexpression of BNIP3 led to dramatic cell death, BNIP3 overexpression did not cause detectable release of cytochrome $c$ from the mitochondria to the cytosol. Cell death induced by BNIP3 overexpression was not blocked by LEHD and ZVAD, specific peptidic inhibitors of caspase- 9 and caspase-3, respectively. This result suggests that neither caspase is implicated in BNIP3induced cell death, which is somewhat unexpected, in light of the ternary complex formed by the $C$. elegans homologs of BNIP3, caspase 3 and $\mathrm{Bcl}-2 .{ }^{35}$ However, the literature is divided with respect to the requirements for induction of apoptosis by BNIP3, and the underlying molecular mechanisms are unclear. Thus, Ray et al. ${ }^{39}$ identified the transmembrane domain and excluded the $\mathrm{BH} 3$ domain of BNIP3 as critical for interaction with $\mathrm{Bcl}-2$ and induction of cell killing. Their results also suggested that mitochondrial targeting of BNIP3 was not strictly required for induction of cell death. In contrast, mutational analysis by other investigators demonstrated a requirement for the BNIP3 $\mathrm{BH} 3$ domain $^{38,42}$ and mitochondrial targeting ${ }^{27,42}$ for induction of cell death. BNIP3-induced apoptosis is inhibited by an unknown mechanism by $\mathrm{B} 5$, a $\mathrm{BH} 3$ domain-containing cellular protein that interacts with both BNIP3 and the adenovirus E1B $19 \mathrm{kDa}$ protein. ${ }^{43}$ Our data with peptidic caspase inhibitors indicate that BNIP3 induced cell death does not involve either caspase 3 and 9, which have otherwise been implicated in many apoptotic cascades (reviewed $\mathrm{in}^{4,16,40}$ ). However, this result does not rule out the possibility that other caspases may be involved in BNIP3-induced cell death. Altogether, our data and the literature is consistent in ascribing a pro-apoptotic role to BNIP3, however the mechanisms and requirements for BNIP3 induced cell death are presently unclear and will require additional investigation. The most recent results published by Vande Velde and co-authors ${ }^{36}$ indicate that BNIP3 may cause necrosis-like cell death through the mitochondrial permeability transition pores. Authors also found that BNIP3-mediated cell death was independent of APAF-1, caspase activation and cytochrome $c$ release.

It had been previously demonstrated that hypoxia induces programmed cell death in cell culture models such as neonatal cardiomyocytes. ${ }^{44,45}$ However, the molecular mechanism through which hypoxia induces apoptosis is far from clear. Through microarray analysis of a neonatal rat cardiomyocyte subtracted cDNA library, we demonstrated that expression of the pro-apoptotic gene $B N I P 3$ is dramatically upregulated during hypoxia. This 
observation suggested that this gene may be at least partially responsible for the induction of apoptosis during oxygen deprivation. Our data show that the mechanism by which hypoxia stimulates expression of BNIP3 is most likely through direct activation of HIF1, similar to the mechanism of hypoxic induction of EPO, VEGF-A, and glycolytic enzymes. $^{21}$ Whether BNIP3 transcripts are increased primarily as a result of hypoxia-induced increased rate of transcription, mRNA stabilization or both remains to be determined. During revision of this manuscript, the promoter of the BNIP3 gene was cloned and shown to contain canonical HREs indispensible for BNIP3 induction by hypoxia. Induction of BNIP3 by hypoxia was demonstrated in six cell lines from three different species. ${ }^{46}$ Thus, upregulation of BNIP3 expression by hypoxia is at least partly due to increased BNIP3 transcription. In addition, a good correlation was found between BNIP3 accumulation and cell death progression, although no mechanistic studies of cell killing were performed. ${ }^{46}$ Thus, these recent results and ours are highly complementary.

HIF1 has been suggested as a potential regulator of hypoxia induced apoptotic cell death. ${ }^{23}$ Cells derived from $\mathrm{HIF} 1 \alpha^{-1-}$ mice were shown to be more resistant to hypoxia insult, compared to wild type $\mathrm{HIF} 1 \alpha^{+/+}$cells. Our data allow speculation that the resistance $\mathrm{HIF} 1 \alpha^{-/-}$cells to hypoxiainduced cell death may be due, at least partially, to inability of hypoxia to upregulate BNIP3 in cells lacking HIF1 $\alpha$.

Multiple mechanisms determine whether an anti- or proapoptotic program is active under every specific condition, including hypoxia. Transcriptional regulation of apoptosisrelated genes enables cells to adapt their responses to a particular stimulus, with the outcome either rendering the cells more or less susceptible to programmed cell death. Our data show that, in response to hypoxia, BNIP3 is strongly upregulated in cardiomyocytes and other cell types, and under these conditions, a pro-apoptotic program is favored. Increased understanding of the mechanisms of BNIP3 upregulation and induction of cell death could help to design new therapeutic strategies in stroke, ischemia, heart failure, and other pathologies in which hypoxia contributes to cell death and loss of organ function.

\section{Materials and Methods}

\section{Tissue culture}

HeLa cells were maintained in DME media supplemented with $10 \%$ fetal bovine serum. Neonatal rat cardiomyocytes were isolated by using Neonatal Cardiomyocyte Isolation System (Worthington Biochemical Corporation, Lakewood, NJ, USA). Basically, minced hearts were digested with trypsin at $4^{\circ} \mathrm{C}$ overnight. The next morning, after addition of trypsin inhibitor and warming to $37^{\circ} \mathrm{C}$, samples were digested with collagenase at $37^{\circ} \mathrm{C}$ with slow shaking. After gentle, up and down pipetting ( $\sim 10$ times), samples were filtered to remove nondigested materials. Cells were collected by centrifugation at $100 \times g$ for $5 \mathrm{~min}$, and washed with L-15 solution twice. Cells were resuspended in plating media (DMEM:M199=4:1, $1 \times$ Insulin-Trans-

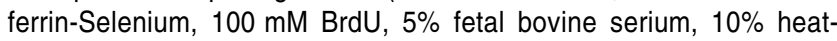

inactivated horse serum) and plated on collagen-I coated tissue culture plates overnight at a density of $3 \times 10^{6}$ cells $/ 10 \mathrm{~cm}$ plate. Cells were washed with $1 \times$ PBS before switching to new media.

Hypoxia treatment Cells were incubated at $37^{\circ} \mathrm{C}$ in oxygen free conditions $\left(85 \% \mathrm{~N}_{2}, 5 \% \mathrm{CO}_{2}, 10 \% \mathrm{H}_{2}\right)$ for the indicated times using the Anaerobic System (Forma Scientific).

\section{RNA isolation}

Cellular total RNA was isolated using Ultraspec RNA Isolation reagents (Biotec Laboratories, Inc.) according to the manufacturer's instructions. Basically, cells were briefly washed with $1 \times$ PBS, and $1 \mathrm{ml}$ of pre-warmed Ultraspec reagent was added to each $10 \mathrm{~cm}$ tissue culture plate. Cells were scraped from plates and transfered to $1.5 \mathrm{ml}$ centrifuge tubes, $0.2 \mathrm{ml}$ of chloroform added and samples vortexed briefly. After centrifugation at $4^{\circ} \mathrm{C}$, the upper liquid phase was collected and an equal volume of isopropanol added. RNA was precipitated by centrifugation at $4{ }^{\circ} \mathrm{C}$, and the RNA pellet was washed with $75 \%$ ethanol. After brief drying by speed-vacuum, the RNA pellet was dissolved in DEPC-treated water at $65^{\circ} \mathrm{C}$ for $30 \mathrm{~min}$.

\section{Generation of hypoxic rat neonatal cardiomyocyte subtracted cDNA library}

Five hundred $\mu \mathrm{g}$ of total RNA from both normal and $24 \mathrm{~h}$ hypoxia treated cells were oligo-dT selected. Two $\mu \mathrm{g}$ of the resulting mRNA from each set was used to generate double stranded cDNA for use in the PCR-Select ${ }^{\mathrm{TM}}$ (Clontech) suppression subtractive hybridization (SSH) method. Using the normal cardiomyocyte cDNA as driver and the cDNA from the hypoxic cardiomyocytes as tester, a SSH library was generated which is enriched for transcripts which are upregulated in response to hypoxia. Prior to cloning, the final amplified library PCR products were incubated with 5 units of Taq polymerase (Life Technologies) and $500 \mathrm{nM}$ dNTPs for $30 \mathrm{~min}$ at $68^{\circ} \mathrm{C}$ to assure that all cDNA ends included a dA tail for cloning into the T/A vector pCR2.1 (Invitrogen). The cDNA library was then ligated into pCR2.1 and the ligation reaction was used to transform the competent $E$. coli strain TOP10 (Invitrogen). Eight thousand individual colonies were picked, plasmid DNA isolated, and cDNA inserts sequenced.

\section{Fabrication of cDNA microarray}

Plasmid DNA (8000 individual clones) from the rat hypoxic cardiomyocyte library was amplified with Amplitaq Gold DNA polymerase (Perkin-Elmer) using primers flanking the multiple cloning site in pCR2.1. The PCR products were verified by agarose gel electrophoresis and purified with Qiaquick 96-well purification kits (Qiagen). The purified products were dried and resuspended in water/ DMSO $(1: 1 \mathrm{v} / \mathrm{v})$ to a final concentration of $200 \mathrm{fmol} / \mu \mathrm{l}$. PCR products were spotted onto Type 7 aluminum-coated glass slides (Amersham Pharmacia Biotech) using a Molecular Dynamics Genlll spotter. After drying, the DNA on the slide was UV-crosslinked at 50 millijoules. The cDNA inserts of 3840 genes from the library, together with positive and negative control DNAs were spotted in duplicate on a typical slide.

\section{Preparation of fluorescent cRNA probes, hybridization and scanning}

Double stranded cDNA was generated from total RNA (10 $\mu \mathrm{g})$ by the SuperScript Choice System (GibcoBRL) using an oligo-dT primer containing the T7 promoter sequence for first strand CDNA synthesis. Cy3- and Cy5-labeled cRNA probes were prepared by in vitro 
transcription of second strand cDNA using the T7 Megascript TM kit from Ambion. The labeled cRNAs were purified with the RNAeasy min kit (Qiagen). Slides were hybridized to Cy3 or Cy5 labeled cRNA probes $(1 \mu \mathrm{g} / \mathrm{slide})$ from control and hypoxic cells, in $38 \mu \mathrm{l}$ of hybridization buffer version 2 (Amersham Pharmacia Biotech) containing $50 \%$ formamide at $42^{\circ} \mathrm{C}$ for $16 \mathrm{~h}$ under a cover slip. At the end of hybridization, cover slips were removed and slides were washed at $55^{\circ} \mathrm{C}$ sequentially in $1 \times \mathrm{SSC} / 0.1 \%$ SDS, $0.1 \times \mathrm{SSC} / 0.1 \%$ SDS and $0.01 \times \mathrm{SSC} / 0.1 \% \mathrm{SDS}$, rinsed in water, ethanol, and then dried. Slides were scanned in a Genelll Array Scanner (Molecular Dynamics) and the intensity of the spots on the slide was quantified with ArrayVision software (Imaging Research Inc.). In a typical experiment, four replicate slides were used for each labeling condition (Cy3 control, Cy5 hypoxia) and another four slides for the reversed labeling condition (Cy5 control, Сy3 hypoxia). Thus, a total of eight slides with 16 replicate spots were used for each analysis. For data analysis, the ratio of the relative normalized signal intensities of control and hypoxia samples was calculated for each spot. A $1 \times$ standard deviation filter was applied to the 16 replicate values to reject outliers. The surviving replicate values within the $1 \times$ standard deviation range were then averaged.

\section{Northern blot analysis}

Radiolabeled probes were generated from $50 \mathrm{ng}$ of the indicated cDNA inserts by random priming, according to the manufacturer's instructions (Boehringer Mannheim). Probes were purified by spin column chromatography according to the manufacturer's instructions (Bio-Rad). Blots were hybridized with probes in ExpressHyb hybridization solution (Clontech) at $68^{\circ} \mathrm{C}$ for $1 \mathrm{~h}$. After hybridization, blots were washed twice in 2 XSSC, $0.05 \%$ SDS at room temperature (20 min for each wash) followed by one wash at $50^{\circ} \mathrm{C}$ for $30 \mathrm{~min}$ in $0.1 \%$ SSC, $0.1 \%$ SDS. After washing, blots were exposed to Kodak Xray film overnight at $-80^{\circ} \mathrm{C}$.

\section{Construction of adenoviral vectors expressing BNIP3, $\beta$-galactosidase, and p53}

Recombinant adenoviruses were constructed by the method described by Crouzet et al. ${ }^{47}$ Briefly, cDNAs of interest were subcloned into the expression cassette in plasmid vector pXL2996 under the control of the CMV promoter. Each expression cassette was subcloned into the shuttle vector $\mathrm{pXL3474}$. The resulting shuttle plasmids were introduced into E. coli JM83 cells by electroporation. After double homologous recombinations, plasmid DNA for recombinant virus was purified by $\mathrm{CsCl}$ density gradient centrifugation. This DNA was linearized by restriction enzyme digestion and transfected into 293 cells using LipofectAmine (Life Technologies). Two to three weeks after transfections, recombinant adenovirus was harvested from the conditioned media and amplified in 293 cells. The concentration of recombinant adenovirus stocks was determined by standart plaque assay method.

For the most of experiments the cells were infected with adenoviruses at a multiplicity of infection (MOI) of 10-30 viral particles per cell for $12 \mathrm{~h}$ before media has been changed.

\section{Generation of antibodies}

Two peptides from human BNIP3 QHESGRSSSKSSHCDS (residues 51-66, peptide 12/2) and RSQTPQDTNRASETDTHS (residues 6986 , peptide 13/2) were synthesized, coupled to keyhole limpet hemocyanin and used to produce polyclonal antibodies in rabbits
(Rockland Immunochemicals). Anti-BNIP3/12-2 and anti-BNIP3/13-2 were shown to recognize denatured BNIP3 from cells overexpressing human BNIP3 (data not shown) and anti-BNIP3/12/2 was used for immunoblotting as described below.

\section{Immunoblotting analysis}

Whole cell lysates Cells were grown in 6-well $(35 \mathrm{~mm})$ plates (Corning) and after appropriate treatments (hypoxia, transfection, etc.) washed once with phosphate-buffered saline (PBS) and lysed in SDS sample buffer.

Fractionated cell lysates To separate cytosolic and mitochondrial fractions, cells were grown in $10 \mathrm{~cm}$ plates and after appropriate treatments, washed with PBS and scraped into buffer containing $50 \mathrm{mM}$ HEPES, $\mathrm{pH} 7.4,150 \mathrm{mM} \mathrm{NaCl}, 10 \mathrm{mM} \mathrm{MgCl}_{2}$, and a mixture of protease inhibitors (Boehringer). After Dounce homogenization (10 strokes), mitochondria, together with cytoplasmic membranes were separated by centrifugation in a table-top centrifuge at 14,000 r.p.m. for $30 \mathrm{~min}$. Pellets containing mitochondria and cytoplasmic membranes were resuspended in PBS in a volume equal to the supernatant (containing cytosol and endoplasmatic reticulum) volume. Equal aliquots of resuspended pellets and supernatant were mixed with $2 \times$ SDS sample buffer. After boiling, samples were fractionated by SDS-polyacrylamide gel electrophoresis (SDS-PAGE) and electrotransferred to nitrocellulose membranes. After blocking with Tris-buffered saline (TBS), $\mathrm{pH} 7.4,0.2 \%$ Tween 20, 5.0\% non-fat dry milk (blocking solution) overnight at $4^{\circ} \mathrm{C}$, blots were incubated with primary antibodies $(1: 1000)$ at room temperature in blocking solution. Following washing with blocking solution three times, blots were incubated with a 1:2500 dilution of HRP-conjugated goat anti-rabbit antibodies in blocking solution (SantaCruz Biotechnology, CA, USA) for $2 \mathrm{~h}$. Membranes were then washed three times with blocking solution, three times with 1XTBS/ $0.2 \%$ Tween20, and immunoreactive bands were visualized with the enhanced chemiluminescence (ECL) Western blotting detection system (Pierce).

\section{Measurement of apoptosis}

HeLa cells were seeded into 6-well plates and transfected on the following day with $0.1 \mu \mathrm{g}$ of pCMV- $\beta$-gal by the Lipofectamine method $(B R L)$. After $6 \mathrm{~h}$, the cells were washed once with DMEM and infected with the indicated amounts of adenoviruses in DMEM supplemented with $10 \%$ fetal calf serum. Twenty-four hours later, cells were washed with PBS, fixed for 5 min on ice with $4 \%$ paraformaldehyde in PBS, washed three times and $\beta$-galactosidase-positive cells were stained (in the dark) using $X$-gal solution $(0.04 \% \mathrm{w} / \mathrm{v})$ in PBS containing potassium ferrocyanide $(5 \mathrm{mM})$ and potassium ferricyanide $(5 \mathrm{mM})$. After overnight staining, cells were washed and blue cells were counted at $200 \times$ magnification. The percentage of $\beta$-gal-positive cells with apoptotic morphology (condensed or fragmented nuclei, membrane blebbing) was calculated after counting $200 \beta$-gal positive cells per sample.

\section{Acknowledgements}

We acknowledge Steve French and Joe Bruno for their help with sequencing the subtracted library, Karine Berthelot for the preparation of cDNA arrays and Dmitri Ivashchenko for sequences analysis. 


\section{References}

1. Hengartner MO, Ellis RE and Horvitz HR (1992) Caenorhabditis elegans gene ced-9 protects cells from programmed cell death. Nature 356: 494-499

2. Hengartner MO and Horvitz HR (1994) Activation of C. elegans cell death protein CED-9 by an amino-acid substitution in a domain conserved in Bcl-2. Nature 369: 318-320

3. Hengartner MO and Horvitz HR (1994) C. elegans cell survival gene ced-9 encodes a functional homolog of the mammalian proto-oncogene bcl-2. Cell 76: 665-676

4. Vander Heiden MG and Thompson CB (1999) Bcl-2 proteins: regulators of apoptosis or of mitochondrial homeostasis? Nat. Cell Biol. 1: E209-E216

5. Oltvai ZN, Milliman CL and Korsmeyer SJ (1993) Bcl-2 heterodimerizes in vivo with a conserved homolog, Bax, that accelerates programmed cell death. Cell 74: $609-619$

6. Gross A, Jockel J, Wei MC and Korsmeyer SJ (1998) Enforced dimerization of BAX results in its translocation, mitochondrial dysfunction and apoptosis. EMBO J. 17: 3878-3885

7. Krajewski S, Tanaka S, Takayama S, Schibler MJ, Fenton W and Reed JC (1993) Investigation of the subcellular distribution of the bcl-2 oncoprotein: residence in the nuclear envelope, endoplasmic reticulum, and outer mitochondrial membranes. Cancer Res. 53: 4701-4714

8. Nguyen M, Branton PE, Walton PA, Oltvai ZN, Korsmeyer SJ and Shore GC (1994) Role of membrane anchor domain of $\mathrm{Bcl}-2$ in suppression of apoptosis caused by E1B-defective adenovirus. J. Biol. Chem. 269: 16521 - 16524

9. Marchetti P, Castedo M, Susin SA, Zamzami N, Hirsch T, Macho A, Haeffner A, Hirsch F, Geuskens M and Kroemer G (1996) Mitochondrial permeability transition is a central coordinating event of apoptosis. J. Exp. Med. 184: 11551160

10. Zamzami N, Susin SA, Marchetti P, Hirsch T, Gomez-Monterrey I, Castedo Mand Kroemer G (1996) Mitochondrial control of nuclear apoptosis [see comments]. J. Exp. Med. 183: 1533-1544

11. Liu X, Kim CN, Yang J, Jemmerson R and Wang X (1996) Induction of apoptotic program in cell-free extracts: requirement for dATP and cytochrome c. Cell 86 : $147-157$

12. Kluck RM, Bossy-Wetzel E, Green DR and Newmeyer DD (1997) The release of cytochrome c from mitochondria: a primary site for $\mathrm{Bcl}-2$ regulation of apoptosis [see comments]. Science 275: 1132-1136

13. Yang J, Liu X, Bhalla K, Kim CN, Ibrado AM, Cai J, Peng TI, Jones DP and Wang X (1997) Prevention of apoptosis by Bcl-2: release of cytochrome c from mitochondria blocked [see comments]. Science 275: 1129-1132

14. Chinnaiyan AM, O'Rourke K, Lane BR and Dixit VM (1997) Interaction of CED-4 with CED-3 and CED-9: a molecular framework for cell death [see comments]. Science 275: $1122-1126$

15. Cain K, Bratton SB, Langlais C, Walker G, Brown DG, Sun XM and Cohen GM (2000) Apaf-1 oligomerizes into biologically active $\sim 700-\mathrm{kDa}$ and inactive $\sim 1.4$ MDa apoptosome complexes. J. Biol. Chem. 275: 6067-6070

16. Kuida K (2000) Caspase-9 [In Process Citation]. Int. J. Biochem. Cell Biol. 32 $121-124$

17. Hsu YT, Wolter KG and Youle RJ (1997) Cytosol-to-membrane redistribution of Bax and $\mathrm{Bcl}-\mathrm{X}(\mathrm{L})$ during apoptosis. Proc. Natl. Acad. Sci. USA 94: 3668-3672

18. Sabbah HN, Sharov VG and Goldstein S (1998) Programmed cell death in the progression of heart failure. Ann. Med. 30: 33-38

19. Snider BJ, Gottron FJ and Choi DW (1999) Apoptosis and necrosis in cerebrovascular disease. Ann. NY. Acad. Sci. 893: 243-253

20. Iyer NV, Kotch LE, Agani F, Leung SW, Laughner E, Wenger RH, Gassmann M, Gearhart JD, Lawler AM, Yu AY and Semenza GL (1998) Cellular and developmental control of $\mathrm{O} 2$ homeostasis by hypoxia-inducible factor 1 alpha. Genes Dev. 12: 149-162

21. Wenger RH and Gassmann M (1997) Oxygen(es) and the hypoxia-inducible factor-1. Biol. Chem. 378: 609-616

22. Jiang BH, Zheng JZ, Leung SW, Roe Rand Semenza GL (1997) Transactivation and inhibitory domains of hypoxia-inducible factor 1 alpha. Modulation of transcriptional activity by oxygen tension. J. Biol. Chem. 272: 19253-19260

23. Carmeliet $P$, Dor $Y$, Herbert JM, Fukumura D, Brusselmans $K$, Dewerchin $M$, Neeman M, Bono F, Abramovitch R, Maxwell P, Koch CJ, Ratcliffe P, Moons L, Jain RK, Collen D, KeshertE and KeshetE (1998) Role of HIF-1 alpha in hypoxiamediated apoptosis, cell proliferation and tumour angiogenesis [published erratum appears in Nature 1998 Oct 1;395(6701):525]. Nature 394: 485-490
24. Kotch LE, lyer NV, Laughner E and Semenza GL (1999) Defective vascularization of HIF-1 alpha-null embryos is not associated with VEGF deficiency but with mesenchymal cell death. Dev. Biol. 209: 254-267

25. An WG, Kanekal M, Simon MC, Maltepe E, Blagosklonny MV and Neckers LM (1998) Stabilization of wild-type p53 by hypoxia-inducible factor 1 alpha. Nature 392: $405-408$

26. Ravi R, Mookerjee B, Bhujwalla ZM, Sutter CH, Artemov D, Zeng Q, Dillehay LE, Madan A, Semenza GL and Bedi A (2000) Regulation of tumor angiogenesis by p53-induced degradation of hypoxia-inducible factor 1 alpha. Genes. Dev. 14: $34-44$

27. Chen G, Ray R, Dubik D, Shi L, Cizeau J, Bleackley RC, Saxena S, Gietz RD and Greenberg AH (1997) The E1B 19K/Bcl-2-binding protein Nip3 is a dimeric mitochondrial protein that activates apoptosis. J. Exp. Med. 186: 1975-1983

28. BoydJM, MalstromS, Subramanian T, Venkatesh LK, SchaeperU, Elangovan B, D'Sa-Eipper C and Chinnadurai G (1994) Adenovirus E1B 19 kDa and Bcl-2 proteinsinteractwith acommonset of cellularproteins [seecomments] [published erratum appears in Cell 1994 Dec 16;79(6):following 1120]. Cell 79: 341-351

29. Dibbens JA, Miller DL, Damert A, Risau W, Vadas MA and Goodall GJ (1999) Hypoxic regulation of vascular endothelial growth factor $m R N A$ stability requires the cooperation of multiple RNA elements. Mol. Biol. Cell 10: 907-919

30. Chen G, Cizeau J, Vande Velde C, ParkJH, Bozek G, Bolton J, Shi L, Dubik D and Greenberg A (1999) Nix and Nip3 form a subfamily of pro-apoptotic mitochondrial proteins. J. Biol. Chem. 274: 7-10

31. Forsythe JA, Jiang BH, lyer NV, Agani F, Leung SW, Koos RD and Semenza GL (1996) Activation of vascular endothelial growth factor gene transcription by hypoxia-inducible factor 1. Mol. Cell. Biol. 16: 4604-4613

32. Graeber TG, Peterson JF, Tsai M, Monica K, Fornace AJ, Jr and Giaccia AJ (1994) Hypoxia induces accumulation of p53 protein, but activation of a G1phase checkpoint by low-oxygen conditions is independent of p53 status. Mol. Cell. Biol. 14: 6264-6277

33. Miyashita T, Krajewski S, Krajewska M, Wang HG, Lin HK, Liebermann DA, Hoffman B and Reed JC (1994) Tumor suppressor $p 53$ is a regulator of bcl-2 and bax gene expression in vitro and in vivo. Oncogene 9: 1799-1805

34. Sayah DN, Soo C, Shaw WW, Watson J, Messadi D, Longaker MT, Zhang X and Ting K (1999) Downregulation of apoptosis-related genes in keloid tissues. J. Surg. Res. 87: 209-216

35. Yasuda M, D'Sa-Eipper C, Gong XL and Chinnadurai G (1998) Regulation of apoptosis by a Caenorhabditis elegans BNIP3 homolog. Oncogene 17: 25252530

36. Vande Velde C, Cizeau J, Dubik D, Alimonti J, Brown T, Israels S, Hakem R and Greenberg AH (2000) BNIP3 and genetic control of necrosis-like cell death through the mitochondrial permeability transition pore. Mol. Cell. Biol. 20:5454 5468

37. Nicholson DW, Ali A, Thornberry NA, Vaillancourt JP, Ding CK, Gallant M, Gareau Y, Griffin PR, Labelle M, Lazebnik YA, Munday NA, Raju SR, Smulson ME, Yamin TT, Yu VL and MillerDK. (1995) Identification and inhibition of the ICE/ CED-3 protease necessary for mammalian apoptosis [see comments]. Nature 376: $37-43$

38. Yasuda M, Theodorakis $P$, Subramanian $T$ and Chinnadurai G (1998) Adenovirus E1B-19K/BCL-2 interacting protein BNIP3 contains a BH3 domain and a mitochondrial targeting sequence. J. Biol. Chem. 273: 12415-12421

39. Ray R, Chen G, Vande Velde C, Cizeau J, Park JH, Reed JC, Gietz RD and Greenberg AH (2000) BNIP3 heterodimerizes with $\mathrm{Bcl}-2 / \mathrm{Bcl}-\mathrm{X}(\mathrm{L})$ and induces cell death independent of a Bcl-2 homology $3(\mathrm{BH} 3)$ domain at both mitochondrial and nonmitochondrial sites. J. Biol. Chem. 275: 1439-1448

40. Nicholson DW and Thornberry NA (1997) Caspases: killer proteases. Trends Biochem. Sci. 22: 299-306

41. Desagher S, Osen-Sand A, Nichols A, Eskes R, Montessuit S, Lauper S, Maundrell K, Antonsson B and Martinou JC (1999) Bid-induced conformational change of Bax is responsible for mitochondrial cytochrome $\mathrm{c}$ release during apoptosis. J. Cell. Biol. 144: 891-901

42. Imazu T, Shimizu S, Tagami S, Matsushima M, Nakamura Y, Miki T, Okuyama A and Tsujimoto $Y$ (1999) Bcl-2/E1B $19 \mathrm{kDa}$-interacting protein 3-like protein (Bnip3L) interacts with $\mathrm{bcl}-2 / \mathrm{Bcl}-\mathrm{xL}$ and induces apoptosis by altering mitochondrial membrane permeability. Oncogene 18: 4523-4529

43. Ohi N, Tokunaga A, Tsunoda H, NakanoK, HaraguchiK, Oda K, Motoyama Nand Nakajima T (1999) A novel adenovirus E1B19K-binding protein B5 inhibits apoptosis induced by Nip3 by forming a heterodimer through the C-terminal hydrophobic region. Cell Death Differ. 6: 314-325 
44. Long X, Boluyt MO, Hipolito ML, Lundberg MS, Zheng JS, O'Neill L, Cirielli C Lakatta EG and Crow MT (1997) p53 and the hypoxia-induced apoptosis of cultured neonatal rat cardiac myocytes. J. Clin. Invest. 99: 2635-2643

45. Tanaka M, Ito H, Adachi S, Akimoto H, Nishikawa T, Kasajima T, Marumo F and Hiroe M (1994) Hypoxia induces apoptosis with enhanced expression of Fas antigen messenger RNA in cultured neonatal rat cardiomyocytes. Circ. Res. 75: $426-433$
46. Bruick RK (2000) Expression of the gene encoding the proapoptotic nip3 protein is induced by hypoxia. Proc. Natl. Acad. Sci. USA 97: 9082-9087

47. Crouzet J, Naudin L, Orsini C, Vigne E, Ferrero L, Le Roux A, Benoit P, Latta M, Torrent C, Branellec D, Denefle P, Mayaux JF, Perricaudet M and Yeh P (1997) Recombinational construction in Escherichia coli of infectious adenoviral genomes. Proc. Natl. Acad. Sci. USA 94: 1414-1419 